\title{
Consensus on methods of development of clinical practice guidelines in oncology under the auspices of Maria Sklodowska-Curie National Research Institute of Oncology and the Agency for Health Technology Assessment and Tariff System
}

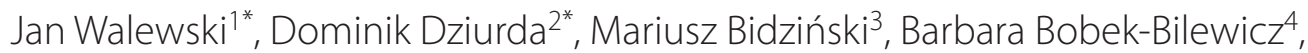 \\ Marek Dedecjus ${ }^{5}$, Iwona Hus ${ }^{6}$, Beata Jagielska ${ }^{7}$, Jacek Jassem ${ }^{8}$, Andrzej Kawecki ${ }^{9}$, \\ Dariusz Kowalski ${ }^{10}$, Magdalena Krasztel ${ }^{2}$, Maciej Krzakowski ${ }^{11}$, Tomasz Kubiatowski ${ }^{12}$, \\ Piotr Potemski13, 14, Radosław Mądry ${ }^{15}$, Piotr Rutkowski ${ }^{16}$, Anna Rychert² , Janusz Ryśs ${ }^{17}$, \\ Krzysztof Składowski ${ }^{18}$, Rafał Tarnawski ${ }^{4}$, Hanna Tchórzewska-Korba ${ }^{19}$, Andrzej Tysarowski20, \\ Piotr J. Wysocki21 , Roman Topór-Mądry²
}

'Department of Lymphoid Malignancies, Maria Sklodowska-Curie National Research Institute of Oncology, Warsaw, Poland

${ }^{2}$ The Agency for Health Technology Assessment and Tariff System (AOTMiT), Warsaw, Poland

${ }^{3}$ Department of Gynecologic Oncology, Maria Sklodowska-Curie National Research Institute of Oncology, Warsaw, Poland

${ }^{4}$ Department of Radiology and Imaging Diagnostics, Maria Sklodowska-Curie National Research Institute of Oncology, Gliwice, Poland

${ }^{5}$ Department of Oncological Endocrinology and Nuclear Medicine, Maria Sklodowska-Curie National Research Institute of Oncology, Warsaw, Poland ${ }^{6}$ Institute of Hematology and Transfusion Medicine, Warsaw, Poland

'Grochowski Hospital, Warsaw, Poland

${ }^{8}$ Department and Clinic of Oncology and Radiotherapy, Medical University, Gdańsk, Poland

${ }^{9}$ Department of Head and Neck Cancer, Maria Sklodowska-Curie National Research Institute of Oncology, Warsaw, Poland

${ }^{10}$ Department of Oncological Radiotherapy and Clinical Oncology, Maria Sklodowska-Curie National Research Institute of Oncology, Warsaw, Poland

${ }^{11}$ Department of Lung Cancer and Chest Tumors, Maria Sklodowska-Curie National Research Institute of Oncology, Warsaw, Poland

${ }^{12}$ Department of Oncology and Immunooncology, Warmian-Masurian Cancer Center of the Ministry of the Interior and Administration's Hospital, Olsztyn, Poland

${ }^{13}$ Chemotherapy Clinic, Oncology Department, Medical University, Lodz, Poland

${ }^{14}$ Nicolaus Copernicus Multidisciplinary Centre of Oncology and Traumatology, Lodz, Poland

${ }^{15}$ Department of Gynecological Oncology, Poznan University of Medical Sciences, Poznan, Poland

${ }^{16}$ Department of Soft Tissue-Bone Sarcoma and Melanoma, Maria Sklodowska-Curie National Research Institute of Oncology, Warsaw, Poland

${ }^{17}$ Department of Pathology, Maria Sklodowska-Curie National Research Institute of Oncology, Krakow Branch, Krakow, Poland

${ }^{18}$ Department of Radiology and Imaging Diagnostics, Maria Sklodowska-Curie National Research Institute of Oncology, Gliwice, Poland

${ }^{19}$ Department of Rehabilitation, Maria Sklodowska-Curie National Research Institute of Oncology, Warsaw, Poland

${ }^{20}$ Independent Laboratory of Genetic and Molecular Diagnostics of Cancer, Maria Sklodowska-Curie National Research Institute of Oncology, Warsaw, Poland

${ }^{21}$ Department and Clinic of Oncology, Jagiellonian University Medical College, Krakow, Poland

* Equal contribution

\section{How to cite:}

Walewski J, Dziurda D, Bidziński M, Bobek-Bilewicz B, Dedecjus M, Hus I, Jagielska B, Jassem J, Kawecki A, Kowalski D, Krasztel M, Krzakowski M, Kubiatowski T, Potemski P, Mądry R, Rutkowski P, Rychert A, Ryś J, Składowski K, Tarnawski R, Tchórzewska-Korba H, Tysarowski A, Wysocki PJ, Topór-Mądry R. Consensus on methods of development of clinical practice guidelines in oncology under the auspices of Maria Sklodowska-Curie National Research Institute of Oncology and the Agency for Health Technology Assessment and Tariff System. NOWOTWORY J Oncol 2022; 72: 44-50.

This article is available in open access under Creative Common Attribution-Non-Commercial-No Derivatives 4.0 International (CC BY-NC-ND 4.0) license, allowing to download articles and share them with others as long as they credit the authors and the publisher, but without permission to change them in any way or use them commercially. 
Introduction. As the changes leading to improvement of cancer care in Poland have shown the need to introduce clinical practice guidelines into the health care system, it has become clear that no methodological standard of the process for guidelines preparation has been established so far. The following process aims to present a unified and comprehensive clinical practice guidelines (CPGs) development methodology.

Materials and methods. A review of globally recognised methods used by guideline development groups was prepared, informing the discussion during three plenary meetings and extensive consultations in writing. The resulting document was unanimously approved by a group of 24 methodologists and clinical experts, and has been formally recognized as a standard for CPGs development by the management of the National Institute of Oncology and the Agency for Health Technology Assessment and Tariff System.

Results. Within the process, 43 recommendations were formulated to create unified and comprehensive rules for guideline development within the Polish healthcare system.

Conclusions. The presented methods are consistent with the globally recognized tools and methods of guideline development, such as GRADE and ADAPTE, and follow quality criteria described by AGREE II. The process supports the development of high-quality guidelines within a resource-constrained setting by allowing to choose between adoption, adaptation, or de novo development of either the whole document of guidelines or particular recommendations.

Key words: practice guidelines, oncology, guidelines development, consensus

\section{Introduction}

Cancer is one of the leading causes of morbidity and mortality worldwide, with an estimated 19.3 million new cancer cases and almost 10.0 million cancer deaths in 2020 [1]. In Europe, the total economic toll from cancer was $€ 199$ billion in 2018 [2]. Thus, it is crucial to provide sufficient expert guidance and resources to address this burden, especially in resource-constrained settings. Worldwide, attempts have been made to help improve access to cancer control, inter alia, by developing clinical practice guidelines (CPGs).

In modern medicine, CPGs play a decisive role in both facilitating the decisions made in specific clinical situations, and influencing the effectiveness and quality of diagnosis and therapy. They constitute a synthesis of the most current, well-founded research that is aimed at identifying the most efficient and safest modes of operating in clinical situations. The CPGs are usually developed by scientific societies, non-governmental organizations as well as governmental institutions.

High-quality guidelines should be based on a transparent process of development and assessment of recommendations, as well as hold the logical connection between alternative therapeutic options and health results, and an appraisal of quality of evidence and strength of recommendations [3, 4]. Thus ensuring the process is systematized, consistent with specific quality criteria, and based on a systematic review of scientific literature, as well as on an assessment of quality and selection of evidence as a basis for the development of recommendations [5].

At the same time, the multitude of organisations that are engaged in guideline production in Poland make it difficult to compare the quality and rigour of CPGs development, as so far no methodological standard of the process has been established. Taking that into consideration and the necessity to introduce a system of quality management into Polish health- care, the need arose to create a unified and comprehensive guideline development methodology.

\section{Materials and methods}

The process was initiated to support the Maria Sklodowska-Curie National Research Institute of Oncology (MSCI) in its statutory activities regarding developing oncology guidelines. It aims to propose the recommended pathway for CPGs development and their effective incorporation into the Polish healthcare system. The process itself is based on the expertise of the clinicians experienced in CPG development, and a review prepared by the Agency for Health Technology Assessment and Tariff System (AOTMiT).

In light of this and in order to propose the best methods, a review of the key solutions for guideline development was prepared by the AOTMiT [6]. The analysis allowed to indicate key areas in the guideline development process, as well as the methods most frequently used by guideline development groups. This served as a basis for further discussion which comprised three on-line meetings and several series of consultations via e-mail. During the meetings, methods for addressing key areas of CPGs development were discussed - both those employed globally by societies producing oncology guidelines, and those recommended by recognized methodological tools and documents (i.e. GRADE, ADAPTE). These allowed the experts to choose - in a series of unanimous votes - solutions in each area best suited to the target conditions.

These decisions allowed for a formulation of the following methodology, which will serve as the basis for the future development of clinical practice guidelines by the National Institute of Oncology. The results of this process were unanimously approved by experts and were formally recognized as a standard by the management of both the National Institute of Oncology and the Agency for Health Technology Assessment and Tariff 
System. The presented methods of guideline development respect the principles of evidence-based medicine for guideline development and take into consideration the available resources and organisational context to ensure relevance for local practice. It is designed to transparently communicate the means and solutions used to produce clinical practice guidelines, their adoptions or adaptations. Topic selection within the process is based on health priorities indicated by the Polish Ministry of Health, scientific societies or other institutions depending on the circumstances.

\section{Methods of guideline development}

\section{Topic selection}

The objective of the guideline should be described in detail including:

- clinical state or health problem,

- population

- intent (i.e., prevention, screening, diagnosis, treatment, etc.),

- expected benefit or outcome,

- target users.

\section{Guideline development group}

Guidelines are developed by an expert group.

- The group is led by a chair appointed by the institution initiating the guideline development process.

- The expert group consists of clinical experts representing fields of medicine relevant to the topic of the guidelines. The chair is responsible for ensuring that all relevant medical specialisations and professions are included.

- The expert group identifies all appropriate stakeholders. If justified, the stakeholders, especially patient representatives, are invited to participate in the work.

- If necessary, EBM analysts are to participate in the process.

- The chair or a designated editor is responsible for editing the document.

- Developed recommendations are subject to approval by the expert group proceeding in full composition of guidelines.

- For each member of the guideline development group, the following information has to be published:

- discipline/content expertise,

- institutional affiliation(s),

- role in the development process, especially the tasks described below.

\section{Conflict of interest}

- Conflicting interests are defined as financial or personal involvement, relationship, affiliation or any other activity that could potentially influence the wording of the guidelines. Group members are obliged to disclose all relationships that may constitute a factual or potential conflict of interest.
- Declaration of Interest is to be submitted to the chair using the form provided in the attachment to this document.

- Each group member is obliged to inform other members of any potential or factual conflict of interests that has a bearing upon the developed recommendation.

- The group member suggests how to manage the conflict of interest described above. The possible actions include exclusion from the discussion, exclusion from the consensus or voting or no restrictions at all. The proposed method is submitted for acceptance from other members.

- In case of a substantial conflict of interest, the member is excluded from the process of recommendation development. A substantial conflict of interest is defined as relationships that amount to 20,000 USD (based on NCCN standards) per year in value, not including participation in clinical trials as a research assistant/investigator.

- Information disclosed in the DOI current for the date of finalizing the development process is published as a part of the guidelines and should include the area and institution of conflict.

\section{Criteria for authorship recognition}

- The authorship should be ascribed only to persons who fulfil all of the following criteria:

- substantial contribution in collection, analysis and interpretation of data serving as the basis for the formulation of recommendations;

- participation in formulation of recommendations or their critical review;

- final acceptance of the document.

\section{Methods of guideline development}

- Guidelines are developed through adoption, adaptation, de novo development or a combination of these methods.

- Choice of the method depends on: guideline topic, availability of current high quality guidelines and available resources.

- The choice of the method is made by the expert group.

- The key health question(s) serving as the basis for the recommendations should be specific, preferably in PICO format.

- If either the whole guideline or particular recommendations are developed de novo, the relevant body of evidence should be gathered in a systematic review of literature.

- In case of adoption or adaptation of the whole guideline or particular recommendations, the process should be held in compliance with ADAPTE [7] or GRADE-ADOLOPMENT [8] tools, or the methods designated by the authors of the source document.

\section{Formulating and accepting recommendations}

- Recommendations are formulated based on the available evidence, taking into account health benefits, side effects and the risk of the intervention. 
- The strengths and limitations of the body of evidence should be clearly described in the context of the recommendation it refers to.

- The process aims to achieve unanimous acceptance of the wording of the recommendations.

- If available evidence is limited, inconsistent, of low quality, does not directly concern the target population, or in other justified situations, the recommendation is formulated through formal consensus.

- The modified Delphi method is the preferred consensus technique, involving the following steps:

- systematic review of evidence for the given health problem,

- formulation of draft recommendation,

- collection and summary of group members'appraisal and opinions,

- a meeting to discuss the results and establish the final wording of the recommendation and level of consensus.

- High level of consensus is considered to have been reached at $85 \%$ agreement, and a moderate level of at least 50\% (but less than 85\%) agreement. Agreement lower than $50 \%$ is recognised as a lack of consensus and the recommendation is not to be published.

\section{Quality of evidence and strength of recommendation}

- The quality of evidence describes the quality of the overall evidence gathered on the clinical profile of the intervention in relation to the PICO question serving as the basis of the recommendation. It defines the level of certainty that the available scientific evidence reflects the true dimensions and direction of effects.

- The quality of evidence is ascribed to every recommendation in accordance with the grading system presented in table I.

- The strength of recommendation defines the degree of conviction that the content of the recommendation should be considered in clinical practice taken into account the conditions of the target healthcare system. The strength of recommendations is a derivative of i.a. quality of evidence, absolute and relative strength of intervention and the level of consensus with regard to implementation in clinical practice.

- The strength of recommendation is ascribed to every recommendation in accordance with the grading system presented in table II.

\section{Presentation of recommendations}

- In order to ensure their unambiguous interpretation, each recommendation should provide a clear and precise description of the population group, clinical description, intervention being recommended, alternative approach(es), and context for which they are intended.
Table I. Quality of evidence

Quality of evidence
\begin{tabular}{|l} 
I \\
evidence from at least one large randomised, controlled trial \\
of good methodological quality (low potential for bias) \\
or meta-analyses well-constructed randomised trials \\
without significant heterogeneity
\end{tabular}
$\begin{aligned} & \text { small randomised trials or large randomised trials with } \\
& \text { a suspicion of bias (lower methodological quality) or meta- } \\
& \text { analyses of such trials or trials with demonstrated significant } \\
& \text { heterogeneity }\end{aligned}$
III $\quad \begin{aligned} & \text { prospective cohort studies } \\
& \text { IV }\end{aligned}$
retrospective cohort studies or case-control studies
studies without a control group, case reports, expert
opinions

Source: The ESMO Guidelines Committee. (2021). Standard Operating Procedures (SOPs) for Authors and templates for ESMO Clinical Practice Guidelines (CPGS) and ESMO-MCBS Scores [9]

Table II. Strength of recommendation

Strength of recommendation
$\begin{array}{ll}\text { recommendation based on high-quality evidence and } \\ \text { a uniform or high-level consensus among the expert group }\end{array}$
$\begin{aligned} & 2 \mathrm{~A} \\ & \text { recommendation based on lower-level evidence and } \\ & \text { a uniform or high-level consensus among the expert group }\end{aligned}$
$\begin{aligned} & \text { recommendation based on lower-level evidence and } \\ & \text { a moderate-level consensus among the expert group }\end{aligned}$
$\begin{aligned} & \text { recommendation based on any level of evidence to which } \\ & \text { the expert group could not reach consensus }\end{aligned}$

${ }^{1}$ Category 3 was introduced to ensure compliance with NCCN guidelines and should be used only in case of NCCN guidelines adoption/adaptation

Source: Own compilation based on The National Comprehensive Cancer Network [10]

- The recommendations should use standardized wording to maintain consistency throughout the guideline.

- Remarks that describe the context, feasibility and applicability of the recommendation should hold an explicit link to the recommendation it refers to.

- Recommendations are presented in a clear form that is easy to follow. For example, they can be numbered, gathered in thematic sections or a summary section, or, optionally, presented as flow charts (preferably using BPMN2).

\section{Review and quality assessment}

- The final draft of guidelines is to be reviewed by all stakeholders mentioned in point: the expert group identifies all appropriate stakeholders. If justified, the stakeholders, especially patient representatives, are invited to participate in the works.

- Quality assessment of guidelines is held using the AGREE II (Appraisal of Guidelines for Research and Evaluation) [4].

- Guidelines should undergo an external peer review by at least two independent reviewers. If the document is to be published in a peer-reviewed journal, this review can substitute for the external peer review. 
- The results of reviews and quality assessment are discussed by the guideline development group. The authors should examine every point and indicate any changes in the document that arise from the process, or if no changes are made, they justify the decision.

\section{Updating the guidelines}

- The expert group is responsible for constant monitoring whether the guideline needs to be updated.

- Ifjustified, particular recommendations are updated, especially when new significant evidence is available, changes in the health care context take place, or a justified motion from the stakeholders is submitted.

- Formal assessment of guideline validity is held every two years.

\section{Glossary of key terms}

- The quality of evidence for a single study refers to the impact of methodological structure of a clinical trial upon uncertainty of estimation of intervention results for a specific endpoint in a specific population in a single study [11].

- The quality of evidence describes the quality of the overall evidence gathered on the clinical profile of the intervention in relation to the defined end point. It defines the level of certainty that the available scientific evidence reflects the true dimensions and direction of effects in the context of the conditions of the target healthcare system. It is also referred to as strength of evidence, trust in estimations, certainty of evidence, or level of evidence, as well as level of strength of evidence [11].

- The strength of intervention refers to the effectiveness of the intervention; it illustrates the magnitude of achievable effect of the new intervention in comparison to other available options in the population subject to the recommendation [11]

- The strength of recommendation defines the degree of conviction that the content of the recommendation should be considered in clinical practice taking into account the conditions of the target healthcare system. It is a derivative of quality of evidence, absolute and relative strength of intervention and the degree of consensus [11].

\section{Discussion}

The approach established within the process allows the development of high-quality guidelines considering the available resources and target healthcare settings, by allowing to choose between adoption, adaptation, as well as de novo development of either the whole guidelines document or particular recommendations.

The suggested process has a number of strengths:

1. It is consistent with recognized tools and methods of guideline development.
2. It is flexible in allowing for the use of different guideline development frameworks depending on the subject and available resources. Thus, existing evidence syntheses can be used, if available, avoiding the necessity of conducting full systematic reviews. At the same time, it helps to identify gaps in knowledge, which might necessitate a systematic review.

3. It allows to build locally contextualized recommendations by involving local experts and stakeholders to ensure that the recommendations address local needs and health care system structure.

While developing the presented approach, the authors sought to ensure that the methods comply with international standards as far as possible within the resources. While there are a number of published standards for guideline development methodology, AGREE II [4] is the most recognized and evidence-based of these [12]. Although the presented Guideline Methodology aims to be consistent with AGREE II, it needs to be noted that not all AGREE II items lie within the scope of NIO's statutory activities; that said, these items (or the reasons for not providing the appropriate data) should still be addressed in the clinical practice guidelines developed within the process (tab. III).

\section{Conclusions}

The presented Methods of Guideline Development were produced in an attempt to introduce a unified and transparent set of methods of guideline development across each branch of medicine (at least) and, hence, to tackle the uncertainties that arise with regard to the diversity of published standards for guideline development methodology. The suggested approach allows to develop high-quality guidelines within a resource-constrained setting, by allowing to choose between adoption, adaptation, or de novo development of either the whole document of guidelines or particular recommendations. At the same time, it is consistent with the recognized tools and methods of guideline development, such as Grading of Recommendations Assessment, Development and Evaluation (GRADE) [13] and ADAPTE [7], and follows key quality criteria described by GIN-McMaster [14] and AGREE II [4].

Conflict of interest: none declared

\section{Piotr Rutkowski}

Maria Sklodowska-Curie National Research Institute of Oncology Department of Soft Tissue-Bone Sarcoma and Melanoma ul. Roentgena 5

02-093 Warszawa, Poland

e-mail: piotr.rutkowski@pib-nio.pl

Received: 21 Oct 2021

Accepted: 26 Oct 2021 
Table III. The sections in presented guideline methodology that address AGREE II items

\begin{tabular}{|c|c|c|}
\hline \multicolumn{2}{|c|}{ AGREE II items } & NIO guideline methodology \\
\hline \multicolumn{3}{|c|}{ Scope and purpose } \\
\hline 1 & the overall objective(s) of the guideline is (are) specifically described & 1. topic selection \\
\hline 2 & $\begin{array}{l}\text { the health question(s) covered by the guideline is (are) specifically } \\
\text { described }\end{array}$ & 4. methods of guideline development \\
\hline 3 & $\begin{array}{l}\text { the population (patients, public, etc.) to whom the guideline is meant } \\
\text { to apply is specifically described }\end{array}$ & 1. topic selection \\
\hline \multicolumn{3}{|c|}{ Stakeholder involvement } \\
\hline 4 & $\begin{array}{l}\text { the guideline development group includes individuals from all } \\
\text { relevant professional groups }\end{array}$ & 1. guideline development group \\
\hline 5 & $\begin{array}{l}\text { the views and preferences of the target population (patients, public, } \\
\text { etc.) have been sought }\end{array}$ & $\begin{array}{l}\text { 1. guideline development group } \\
\text { 8. review and quality assessment }\end{array}$ \\
\hline 6 & the target users of the guideline are clearly defined & 1. topic selection \\
\hline \multicolumn{3}{|c|}{ Rigour of development } \\
\hline 7 & systematic methods were used to search for evidence & 4. methods of guideline development \\
\hline 8 & the criteria for selecting the evidence are clearly described & 4. methods of guideline development \\
\hline 9 & $\begin{array}{l}\text { the strengths and limitations of the body of evidence are clearly } \\
\text { described }\end{array}$ & 5. formulating and accepting recommendations \\
\hline 10 & $\begin{array}{l}\text { the methods for formulating the recommendations are clearly } \\
\text { described }\end{array}$ & 5. formulating and accepting recommendations \\
\hline 11 & $\begin{array}{l}\text { the health benefits, side effects and risks have been considered in } \\
\text { formulating the recommendations }\end{array}$ & 5. formulating and accepting recommendations \\
\hline 12 & $\begin{array}{l}\text { there is an explicit link between the recommendations and the } \\
\text { supporting evidence }\end{array}$ & 5. formulating and accepting recommendations \\
\hline 13 & $\begin{array}{l}\text { the guideline has been externally reviewed by experts prior to its } \\
\text { publication }\end{array}$ & 8. review and quality assessment \\
\hline 14 & a procedure for updating the guideline is provided & 9. updating the guidelines \\
\hline \multicolumn{3}{|c|}{ Clarity of presentation } \\
\hline 15 & the recommendations are specific and unambiguous & 7. presentation of recommendations \\
\hline 16 & $\begin{array}{l}\text { the different options for management of the condition or health issue } \\
\text { are clearly presented }\end{array}$ & 7. presentation of recommendations \\
\hline 17 & key recommendations are easily identifiable & 7. presentation of recommendations \\
\hline \multicolumn{3}{|c|}{ Applicability } \\
\hline 18 & the guideline describes facilitators and barriers to its application & 5. formulating and accepting recommendations \\
\hline 19 & $\begin{array}{l}\text { the guideline provides advice and/or tools on how the } \\
\text { recommendations can be put into practice }\end{array}$ & not applicable \\
\hline 20 & $\begin{array}{l}\text { the potential resource implications of applying the recommendations } \\
\text { have been considered }\end{array}$ & 5. formulating and accepting recommendations \\
\hline 21 & the guideline presents monitoring and/or auditing criteria & not applicable \\
\hline \multicolumn{3}{|c|}{ Editorial independence } \\
\hline 22 & $\begin{array}{l}\text { the views of the funding body have not influenced the content of the } \\
\text { guideline }\end{array}$ & not applicable \\
\hline 23 & $\begin{array}{l}\text { competing interests of guideline development group members have } \\
\text { been recorded and addressed }\end{array}$ & 2. conflict of interest \\
\hline
\end{tabular}

Note: Wherever "not applicable" is used, it is understood as not within the scope of NIO's statutory activities. Particular tasks associated with these quality items are held by other institutions within the Polish healthcare system

\section{References}

1. Sung H, Ferlay J, Siegel RL, et al. Global Cancer Statistics 2020: GLOBOCAN Estimates of Incidence and Mortality Worldwide for 36 Cancers in 185 Countries. CA Cancer J Clin. 2021; 71(3): 209-249, doi: 10.3322/ caac.21660, indexed in Pubmed: 33538338.

2. Hofmarcher $\mathrm{T}$, Lindgren $\mathrm{P}$, Wilking $\mathrm{N}$, et al. The cost of cancer in Europe 2018. Eur J Cancer. 2020; 129: 41-49, doi: 10.1016/j.ejca.2020.01.011, indexed in Pubmed: 32120274
3. Graham R. Institute of Medicine (U.S.), Committee on Standards for Developing Trustworthy Clinical Practice Guidelines. Clinical practice guidelines we can trust. National Academies Press, Washington 2011: xxxiv, 266.

4. Brouwers MC, Kho ME, Browman GP, et al. AGREE Next Steps Consortium. The Global Rating Scale complements the AGREE II in advancing the quality of practice guidelines. J Clin Epidemiol. 2012; 65(5):526-534, doi: 10.1016/j.jclinepi.2011.10.008, indexed in Pubmed: 22189163. 
5. Leśniak W, Bała M, Jaeschke R, et al. Od danych naukowych do praktycznych zaleceń - tworzenie wytycznych według metodologii GRADE. Polish Archives of Internal Medicine. 2015; 125(Special Issue): 26-41, doi: 10.20452/pamw.3232.

6. Agencja Oceny Technologii Medycznych i Taryfikacji. Metodyka opracowywania wytycznych praktyki klinicznej w onkologii. Opracowanie przygotowane w ramach projektu „Wsparcie procesu poprawy jakości w leczeniu onkologicznym oraz zmiana organizacji systemu opieki zdrowotnej w zakresie onkologii. Material not published 2020.

7. The ADAPTE Collaboration. The ADAPTE Process: Resource Toolkit for Guideline Adaptation. Version 2.02009.

8. Schünemann HJ, Wiercioch W, Brozek J, et al. GRADE Evidence to Decision (EtD) frameworks for adoption, adaptation, and de novo development of trustworthy recommendations: GRADE-ADOLOPMENT. J Clin Epidemiol. 2017; 81:101-110, doi: 10.1016/j.jclinepi.2016.09.009, indexed in Pubmed: 27713072

9. European Society for Medical Oncology. Standard Operating Procedures (SOPs) for Authors and templates for ESMO Clinical Practice Guidelines (CPGs) and ESMO-MCBS Scores 2021. https://www.esmo. org/content/download/77789/1426712/file/ESMO-Clinical-PracticeGuidelines-Standard-Operating-Procedures.pdf.
10. The National Comprehensive Cancer Network. About the NCCN Clinical Practice Guidelines in Oncology (NCCN Guidelines ${ }^{\circledast}$ ) 2020. https://www. nccn.org/professionals/default.aspx.

11. Rychert A, Dziurda D, Koperny M, et al. Systems for grading the strength of recommendations in clinical practice guidelines in oncology. Material not published.

12. Yao X, Ma J, Wang Qi, et al. A Comparison of AGREE and RIGHT: which Clinical Practice Guideline Reporting Checklist Should Be Followed by Guideline Developers? J Gen Intern Med. 2020; 35(3): 894-898, doi: 10.1007/s11606-019-05508-3, indexed in Pubmed: 31713037.

13. Guyatt GH, Oxman AD, Vist GE, et al. GRADE Working Group. GRADE: an emerging consensus on rating quality of evidence and strength of recommendations. BMJ. 2008; 336(7650): 924-926, doi: 10.1136/ bmj.39489.470347.AD, indexed in Pubmed: 18436948.

14. Schünemann HJ, Wiercioch W, Etxeandia I, et al. Guidelines 2.0: systematic development of a comprehensive checklist for a successful guideline enterprise. CMAJ. 2014; 186(3): E123-E142, doi: 10.1503/cmaj.131237, indexed in Pubmed: 24344144. 